\title{
COMPARATIVE ANALYSIS OF EFFECT OF THERMAL SHOCK ON ADHESIVE JOINT STRENGTH
}

\author{
Mariusz Kłonica ${ }^{1}$ \\ 1 Department of Production Engineering, Faculty of Mechanical Engineering, Lublin University of Technology, \\ 36 Nadbystrzycka St., 20-618 Lublin, Poland, e-mail: m.klonica@pollub.pl
}

Received: 2016.09.16

Accepted: 2016.10 .18

Published: 2016.12.01

\begin{abstract}
The aim of this study was a comparative analysis of static shear strength of single-lap adhesive joints of $316 \mathrm{~L}$ steel adherends, measured prior to and after mechanical treatment with a P320 grit coated abrasive tool. The study was of comparative nature and focused on adhesive joints subjected to thermal cycling. The tests were carried out on joints bonded with Epidian 5 and Epidian 6 epoxy adhesives hardened with Z1 and PAC curing agents. The static shear strength tests results of single-lap adhesive joints were analysed with regard to different surface treatment variants. The scope of tests covered a relatively short fatigue cycle, i.e. 200 cycles in the range of temperatures between $-40^{\circ} \mathrm{C}$ and $+60^{\circ} \mathrm{C}$. This paper includes the surface free energy and selected surface roughness parameters of substrates and images showing the surface of adherends before and after mechanical treatment with P320 grit coated abrasive tool.
\end{abstract}

Keywords: adhesive joint, epoxy adhesive, thermal cycling.

\section{INTRODUCTION}

Performance of an adhesive joint depends on several factors with proper selection of an adhesive and suitable treatment of adhered surfaces. In order for the selection of adhesive and surface treatment to be considered correct, it must not only account for the properties of substrates but for the future operating conditions of a given adhesive joint. This is dictated by the fact that a number of physical, chemical and biological factors affect joint strength. One of such negative factors is the changing thermal stress. Prolonged exposition to thermal loading leads to degradation of adhesive and might result in thermal fatigue.

Thermal fatigue of adhesive bonded joints is a result of cyclic thermal loading over time and leads to undesirable decrease of strength and expected life of joints, and consequently to abrupt joint failure process at maximum stress whose value is lower than joint static strength [1].

Prolonged operation of adhesive joints affects the cohesive strength of joints as a result of oc- curring ageing processes, which are strictly connected with environmental impact on the joint.

It is also possible to produce hybrid joints that combine adhesive bonding with traditional joining methods, such as pressure welding or riveting [2].

Adhesive layer as a polymer material is a cross-linked system, which under long-term operation acquires viscoelastic properties. Characteristically weak cross-linking of polymers creates "free spaces" in the molecule, whereas their viscoelasticity is responsible for a number of phenomena, including time dependence between stress and strain, which also include strain changes as a result of constant loading or creep behaviour of adhesives.

Cyclic thermal loading consist in changing thermal conditions of the environment where a given adhesive joint is located. The character of such changes can be cyclic or random. In the case of abrupt changes in temperature values, particularly when the temperature gradient is significantly high, the phenomenon is referred to as "thermal shock." Joints subjected to thermal cy- 
Table 1. Chemical composition of 316L steel (based on the material certificate)

\begin{tabular}{|c|c|c|c|c|c|c|c|c|c|}
\hline \multicolumn{10}{|c|}{ 316L steel } \\
\hline Element & $\mathrm{C}$ & $\mathrm{Si}$ & $\mathrm{Mn}$ & $\mathrm{P}$ & $\mathrm{S}$ & $\mathrm{Ni}$ & $\mathrm{Cr}$ & $\mathrm{Mo}$ & $\mathrm{N}$ \\
\hline Value, $\%$ & 0,011 & 0,54 & 1,03 & 0,040 & 0,001 & 10,18 & 16,71 & 2,05 & 0,020 \\
\hline
\end{tabular}

cling are found in such industries as aircraft, automotive, machine building industries, as well as in medicine or electronic industry.

Temperature is of high impact on the strength of adhesive joints [3]. The change in ambient temperature amounting to several dozen centigrade, although of no effect on the properties of metals, can, however, significantly affect properties of high-molecular materials, such as structural adhesives. Cyclic thermal loading has a two-fold effect on adhesive bonded joints: first, they introduce thermal strain to the system and, secondly, alter the mechanical properties of adhesives [4].

The stages of designing and formation of adhesive joints must include proper surface treatment for the adhesive bonding technology [5-10].

The principal aim of this study was to evaluate the response of adhesive lap joint strength to thermal fatigue.

\section{RESEARCH METHODOLOGY}

The dimensions of samples used in adhesive bonding were $25 \times 100 \times 1.5 \mathrm{~mm}$ and the specimens were made of $316 \mathrm{~L}$ steel. In order to produce the desired surface texture and remove the physisorption layer, a part of the investigated samples was mechanically processed with a coated abrasive tool (grain P320) for 30 seconds. All samples were cleaned three times using Loctite 7061 degreaser and cleaning cloth. After the last application of Loctite 7061 the samples were allowed to dry. Table 1 shows the chemical composition of $316 \mathrm{~L}$ steel. The table was prepared on the basis of the material certificate (refer with: Table 1). Table 2 shows selected properties of $316 \mathrm{~L}$ steel - based on the material certificate (refer with: Table 2).

The substrate material selected for the study was the $316 \mathrm{~L}$ steel. The tested single lap adhesive joint specimens were of the following dimensions: adhesive layer thickness $\mathrm{g}_{\mathrm{k}}=0,05 \mathrm{~mm}$ and overlap length $1_{z}=12,5 \mathrm{~mm}$.

The tests were carried out for the following four epoxy adhesive compositions: Epidian 5 $+10 \%$ of Z1 curing agent (triethylenetetramine), Epidian 6
$+10 \%$ Z1, Epidian $5+100 \%$ PAC curing agent and Epidian $6+100 \%$ PAC. Joint curing conditions were specified in all tests: cure temperature $21-22{ }^{\circ} \mathrm{C}$, relative humidity $35-40 \%$, load applied during curing 0,2 MPa and cure time of 120 hours.

200 cycles (thermal shocks) were conducted in thermal shock chamber. The minimum temperature was set to $-40^{\circ} \mathrm{C}$ and the maximum temperature was $+60^{\circ} \mathrm{C}$. The conditioning time of the samples at each temperature level was 15 minutes, excluding the time needed for temperature to stabilise.

Goniometer PGX was used to measure the contact angle on the investigated surfaces of $316 \mathrm{~L}$ steel and to measure the values of the surface free energy (SFE). The liquids used to measure the contact angle were automatically applied on the tested surfaces by the goniometer mechanism as 4 $\mu 1$ (constant volume) drops. Measurements of the contact angle with both distilled water and diiodomethane were repeated minimum 10 times for each tested specimen.

Surface roughness of substrate material was measured with Hommel-Etamic 3D T8000 RC-120-400 roughness, contour and topography measuring system equipped with a $2 \mu \mathrm{m}$ probe. The collected data was analysed with TURBO WAVE software.

Visual images of the substrate surface of $316 \mathrm{~L}$ steel prior to and after mechanical surface treatment were obtained from Keyence VHX5000 microscope.

Shear strength tests of single-lap adhesive joints were performed on Zwick/Roell Z 150 materials testing machine, in accordance with DIN EN 1465. The crosshead speed in the destructive test was $2 \mathrm{~mm} /$ minute with $85 \mathrm{~mm}$ distance between holding fixtures in initial position.

Table 2. Selected properties of 316L steel (based on the material certificate)

\begin{tabular}{|l|l|}
\hline \multicolumn{2}{|c|}{ 316L steel } \\
\hline Tensile strength [MPa] & 592 \\
\hline Yield strength [MPa] & 290 \\
\hline Hardness [HV] & 148 \\
\hline
\end{tabular}


The first phase of the experiment was preliminary tests. The number of necessary measurements in the main tests was defined on the basis of the scatter analysis and assumed materiality level [11]. The number of measurements was derived from the following formula (refer with: Eq. 1):

$$
n=\frac{t_{\alpha}^{2} \cdot s^{2}}{d^{2}} \leq n_{0}
$$

where: $\mathrm{n}_{0}$ - initial sample size,

$\mathrm{t}_{\alpha}-$ value of $\mathrm{t}-$ Student variable,

$\mathrm{s}^{2}-$ initial sample variance,

$d$ - maximum error of the estimate, equals maximum measurement error.

The variance was defined on the basis of the following equation (refer with: Eq. 2):

$$
s^{2}=\frac{\sum_{i=1}^{n}(y i-\bar{y})^{2}}{n-1}
$$

where: yi - output factor value obtained in measurement no. "i", $\bar{y}$ - arithmetic mean, $n$ total number of measurements.

A comparative analysis is usually conducted as a part of experimental tests, which means that, for the assumed materiality level, we examine whether the obtained mean values of the dependent variable in two populations differ significantly. The first phase in verifying the hypothesis of equal means requires verifying the hypothesis of homogeneity of variance. The null hypothesis has the following form (refer with: Eq. 3):

$$
\mathrm{H}_{0}: \sigma_{I}^{2}=\sigma_{I I}^{2}
$$

The alternative hypothesis has the following form (refer with: Eq. 4):

$$
\mathrm{H}_{1}: \sigma_{I I}^{2}<\sigma_{I}^{2}
$$

Statistics based on Fischer-Snedecor distribution was used for verification of the hypothesis (refer with: Eq. 5):

$$
F=\frac{S_{I}^{2}}{S_{I I}^{2}}
$$

where: $\mathrm{S}_{\mathrm{I}}^{2}$ - higher variance, $\mathrm{S}_{\mathrm{II}}^{2}$ - lower variance.

The next phase includes testing the hypothesis of equal means. The null hypothesis has the following form (refer with: Eq. 6):

$$
\mathrm{H}_{0}: m_{1}=m_{2}
$$

The alternative hypothesis has the following form (refer with: Eq. 7):

$$
\mathrm{H}_{1}: m_{1}>m_{2} \text { or } m_{1}<m_{2}
$$

If the variances are equal, the test based on the t-Student distribution is performed in the verification process (refer with: Eq. 8).

$$
t=\frac{\bar{y}_{1}-\bar{y}_{2}}{\sqrt{\frac{\left(n_{1}-1\right) S_{1}^{2}+\left(n_{2}-1\right) S_{2}^{2}}{n_{1}+n_{2}-2}\left(\frac{1}{n_{1}}+\frac{1}{n_{2}}\right)}}
$$

If the verification of the hypothesis of homogeneity of variance indicates that the variances are not equal, the Cochran-Cox test is performed in the verification process (refer with: Eq. 9).

$$
c=\frac{\bar{y}_{1}-\bar{y}_{2}}{\sqrt{\frac{S_{1}^{2}}{n_{1}}+\frac{S_{2}^{2}}{n_{2}}}}
$$

Based on the performed statistical analysis, it is possible to formulate firm conclusions about equality of means and hence about the importance of a given factor/-s at the assumed materiality level.

\section{TEST RESULTS}

Table 3 shows mean values of $316 \mathrm{~L}$ steel surface free energy SFE before and after mechanical treatment with a coated abrasive tool (P320 grit) including calculated standard deviation values. Table 3 also shows SFE components: polar SFE component and dispersion SFE component.

The collated data show a distinct increase in mean value of surface free energy of $316 \mathrm{~L}$ steel substrate following mechanical treatment with a

Table 3. Mean values of surface free energy SFE and its components for $316 \mathrm{~L}$ steel after surface treatment

\begin{tabular}{|c|c|c|c|}
\hline \multirow{2}{*}{} & \multicolumn{3}{|c|}{ 316L steel before machining } \\
\cline { 2 - 4 } & $\begin{array}{c}\text { SFE }[\mathrm{mJ} / \\
\left.\mathrm{m}^{2}\right]\end{array}$ & $\begin{array}{c}\text { Polar } \\
\text { component } \\
\text { of SFE }[\mathrm{mJ} / \\
\left.\mathrm{m}^{2}\right]\end{array}$ & $\begin{array}{c}\text { Dispersive } \\
\text { component } \\
\text { SFE }\left[\mathrm{mJ} / \mathrm{m}^{2}\right]\end{array}$ \\
\hline $\begin{array}{c}\text { Average } \\
\text { value }\end{array}$ & 49,8 & 6,3 & 43,5 \\
\hline $\begin{array}{c}\text { Standard } \\
\text { deviation }\end{array}$ & 1,1 & 1,5 & 1,4 \\
\hline \multicolumn{4}{|c|}{$316 \mathrm{~L}$ steel after machining } \\
\hline $\begin{array}{c}\text { Average } \\
\text { value }\end{array}$ & 61,1 & 15,2 & 45,9 \\
\hline $\begin{array}{c}\text { Standard } \\
\text { deviation }\end{array}$ & 1,2 & 1,1 & 1,6 \\
\hline
\end{tabular}


Table 4. 3D surface roughness parameters of $316 \mathrm{~L}$ steel

\begin{tabular}{|c|c|c|c|c|c|c|}
\hline \multirow{2}{*}{ Surface 316L steel } & \multicolumn{6}{|c|}{ 3D surface roughness parameter } \\
\cline { 2 - 8 } & $\begin{array}{c}\mathrm{Sq} \\
{[\mu \mathrm{m}]}\end{array}$ & $\begin{array}{c}\mathrm{Sp} \\
{[\mu \mathrm{m}]}\end{array}$ & $\begin{array}{c}\text { Sv } \\
{[\mu \mathrm{m}]}\end{array}$ & $\begin{array}{c}\text { Sz } \\
{[\mu \mathrm{m}]}\end{array}$ & $\begin{array}{c}\text { Sa } \\
{[\mu \mathrm{m}]}\end{array}$ & $\begin{array}{c}\text { St } \\
{[\mu \mathrm{m}]}\end{array}$ \\
\hline Before machining & 0,267 & 1,66 & 1,64 & 3,31 & 0,216 & 3,31 \\
\hline After machining & 0,325 & 1,86 & 3,45 & 5,31 & 0,257 & 5,31 \\
\hline
\end{tabular}

coated abrasive tool (P320 grit) when compared to the SFE value before such treatment. The increase was approximately $20 \%$. The dispersion SFE component remained on the same level while the polar SFE component more than doubled after mechanical treatment. The observed increase may have resulted from the removal of surface layer that was formed as a result of exposition to environmental factors (such layer may include oxide layers and adsorbed environmental components contamination). The SFE value was determined in order to verify whether the materials have been properly prepared for bonding.

Figure 1 shows 3D maps of specimen surface before (Fig. a) and after (Fig. b) mechanical treatment with a coated abrasive tool (P320 grit).

a)

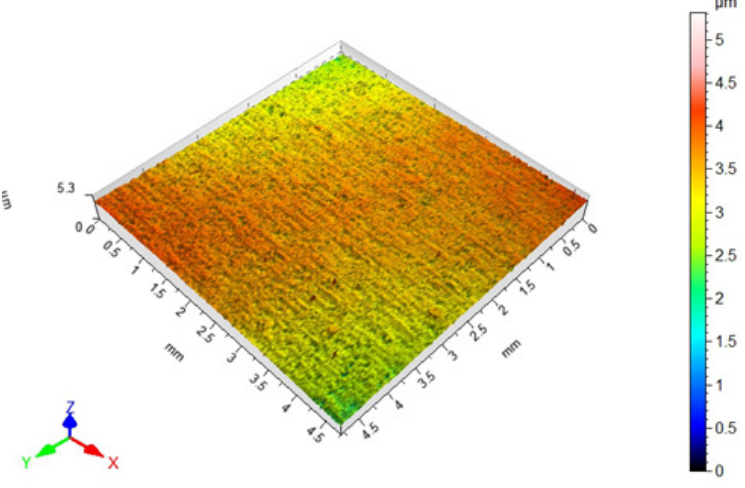

b)

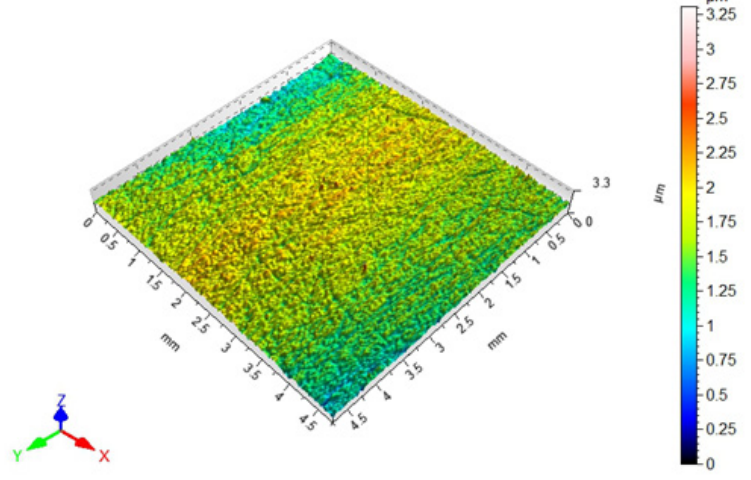

Fig. 1. Isometric projection of substrate surface:

a) before mechanical treatment, b) after mechanical treatment
The presented surface topography maps show typical marks on the surface of adherends typically left by abrasive tool.

Table 4 collates selected 3D surface roughness parameters of 316 steel substrate before and after mechanical treatment with P320 grit coated abrasive tool.

The conducted tests and their results indicate that mechanical treatment has a beneficial effect on 3D surface roughness parameters after mechanical treatment, compared to the surface of untreated specimens.

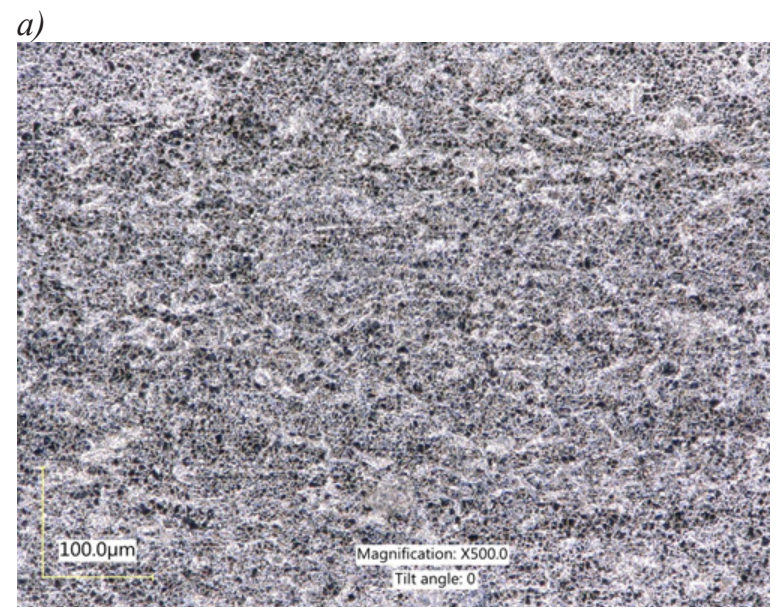

b)

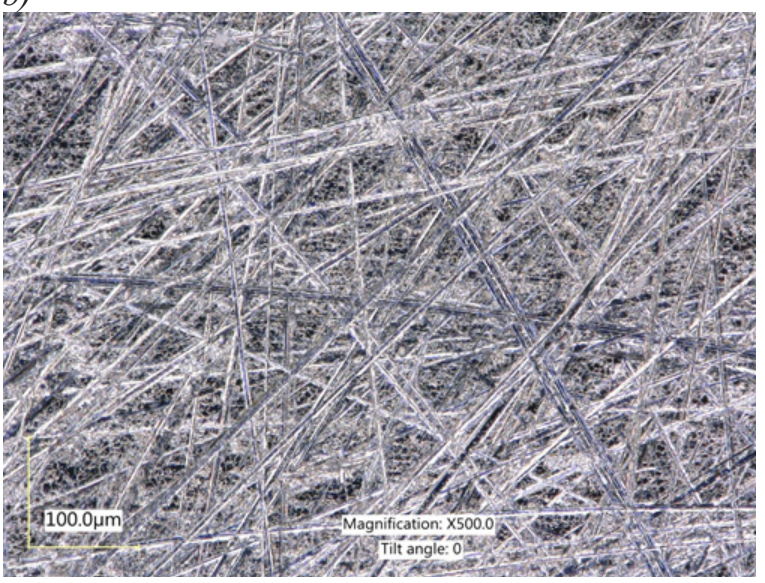

Fig. 2. The view of $316 \mathrm{~L}$ steel substrates at $x 500$ magnification: a) before mechanical treatment,

b) after mechanical treatment with P320 grit coated abrasive tools 
a)
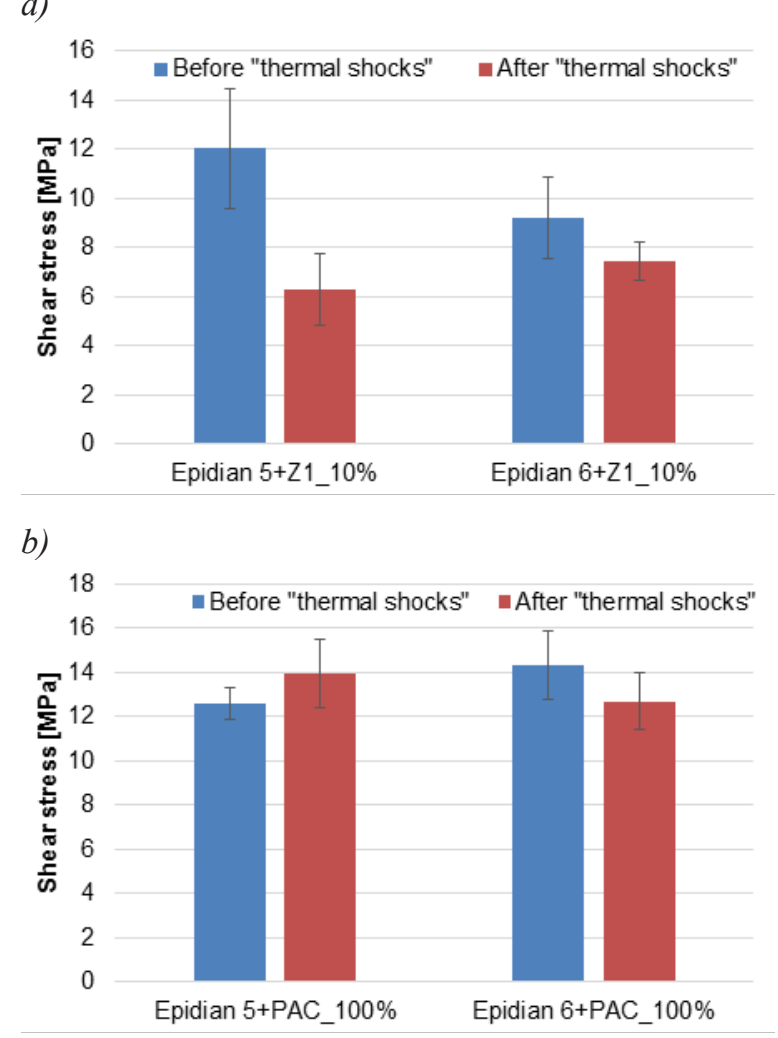

Fig. 3. Shear stress measured in $316 \mathrm{~L}$ steel adhesive joint specimens after mechanical treatment, bonded with different epoxy resins cured with: a) Z1 curing agent, b) PAC curing agent

Figure 2 shows the surface of $316 \mathrm{~L}$ magnified $500 \times$. Figure 2 a shows roughness the surface of samples before and mechanical treatment, which was cleaned and degreased with Loctite 7061 degreasing agent. Figure $2 b$ shows the surface of substrates after mechanical treatment with a coated abrasive tool (P320 grit) with clearly visible marks, characteristic of the treatment method in question.

Figure 3 shows mean values of shear stress in single-lap adhesive joints of $316 \mathrm{~L}$ adherends, measured in tests after mechanical treatment and for different epoxy resin compositions. The specimens were subjected to cyclic thermal loading at a thermal gradient of $100^{\circ}$. In Figures 3 and 4 standard deviation was the measure of scatter.

In joint specimens bonded with adhesive composition based on epoxy resin and cured with Z1 curing agent there was a drop in shear stress value in specimens after thermal shock compared with specimens not subjected to thermal shock. The highest decrease in the shear stress value was observed in the case of joints bonded with Epidian 5 epoxy, and mounted to approximately $50 \%$ of shear stress in joints before thermal shock, whereas in Epidian 6 epoxybased adhesive $-17 \%$. In epoxy-based adhesives cured with PAC curing agent (a relatively elastic adhesive), compared with specimens prior to thermal shock, no such relevant differences in adhesive strength of joints subjected to thermal shock were noted.

Figure 4 shows mean values of shear stress in single-lap adhesive joints of $316 \mathrm{~L}$ adherends, measured in tests after mechanical treatment and for different epoxy resin compositions.

Similarly as in samples not subjected to mechanical surface treatment, the highest recorded decrease in shear stress after thermal shock was observed in joints bonded with Epidian 5 with Z1 curing agent, where the difference amounted to $50 \%$ in comparison with specimens prior to thermal shock. In specimens formed with Epidian 6 with Z1 curing agent, the decrease was smaller $-36 \%$. PAC-cured epoxy adhesives did not show signs of impact of thermal shock on joint strength, as the noted results were comparable.
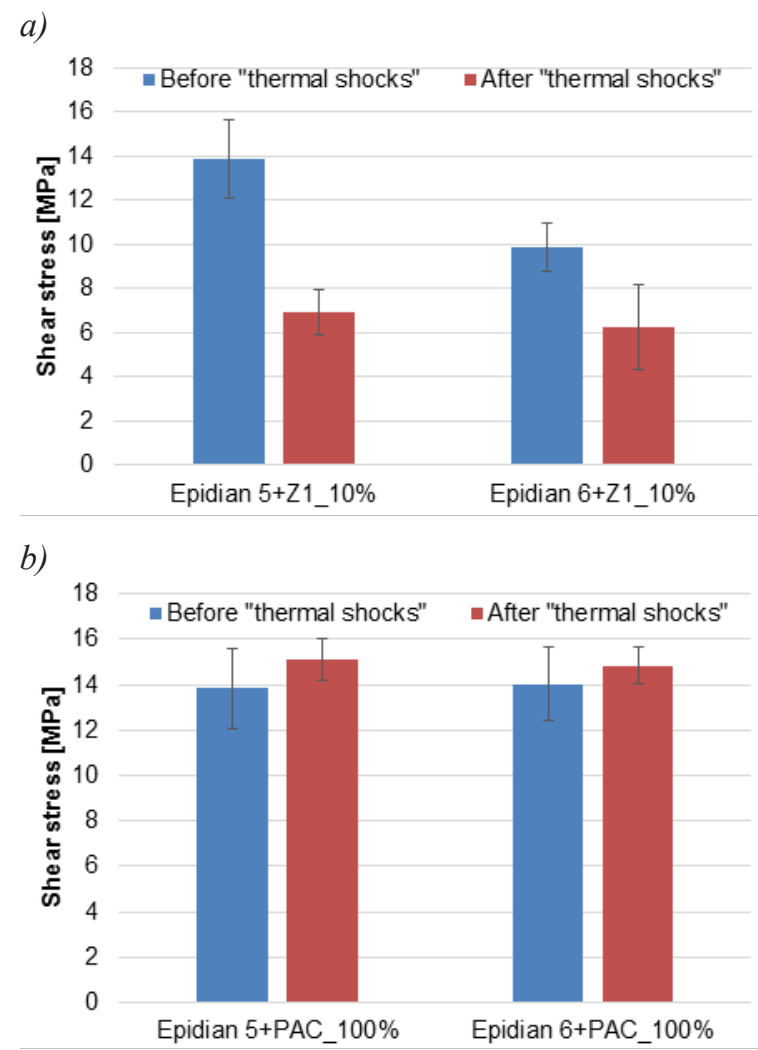

Fig. 4. Shear stress measured in $316 \mathrm{~L}$ steel adhesive joint specimens after mechanical treatment, bonded with different epoxy resins cured with: a) Z1 curing agent, b) PAC curing agent 


\section{CONCLUSIONS}

The tests conducted in the presented study lead to the following conclusions:

1. Mechanical treatment of the surface of $316 \mathrm{~L}$ steel with a P320 grit coated abrasive tool produces the increase of the surface free energy levels by approximately $22 \%$, compared to surfaces prior to treatment. Furthermore, a marked increase, of more than $200 \%$, in the polar component value of the SFE after mechanical treatment was noted.

2. The analysis of isometric images and selected surface roughness parameters indicates that mechanical treatment with coated abrasive tools shows high efficiency in developing the surface roughness.

3. The most significant decrease in the shear stress values following thermal shock was observed in 316L steel specimens bonded with Epidian 5 epoxy adhesive with Z1 curing agent, both prior to and after mechanical treatment; the shear stress in these joints amounted to approximately $50 \%$ of stress in joint specimens prior to thermal shock.

4. An adhesive exhibiting the highest resistance to cyclic thermal loading was the PAC-cured epoxy adhesive.

\section{REFERENCES}

1. Godzimirski J. Problemy klejenia konstrukcyjnego. Technologia i Automatyzacja Montażu, 1, 2009, 25-31.

2. Sadowski T., Balawender T., Śliwa R., Golewski P. and Kneć M. Modern hybrid joints in aerospace: modeling and testing. Archives of Metallurgy and Materials, 58(1), 2013, 163-169.

3. Kłonica M. Impact of thermal fatigue on Young's modulus of epoxy adhesives. Advances in Science and Technology Research Journal, 9(28), 2015, 103-106.

4. Humfeld G. R., Jr. Mechanical behavior of adhesive joints subjected to thermal cycling. Virginia Polytechnic Institute, Blacksburg, Virginia, 1997.

5. Kuczmaszewski J. Fundamentals of metal-metal adhesive joint design. Politechnika Lubelska, Oddział PAN w Lublinie, Lublin, 2006.

6. Kłonica M., Kuczmaszewski J., Kwiatkowski M. and Ozonek J. Polyamide 6 surface layer following ozone treatment. International Journal of Adhesion and Adhesives, 64, 2016, 179-187.

7. Kwiatkowski M. P., Kłonica M., Kuczmaszewski J. and Satoh S. Comparative analysis of energetic properties of Ti6Al4V titanium and EN-AW2017A(PA6) aluminum alloy surface layers for an adhesive bonding application. Ozone: Science\& Engineering: The Journal of the International Ozone Association, 35(3), 2013, 220-228.

8. Fic S., Kłonica M. and Szewczak A. Adhesive properties of low molecular weight polymer modified with nanosilica and disintegrated ultrasonically for application in waterproofing ceramics. Polimery, 60(11-12), 2015, 730-734.

9. Żenkiewicz M. Comparative study on the surface free energy of a solid calculated by different methods. Polymer Testing, 26(1), 2007, 14-19.

10. Żenkiewicz M. Methods for the calculation of surface free energy of solids. Journal of Achievements in Materials and Manufacturing Engineering, 24(1), 2007, 137-145.

11. Korzyński M. Metodyka eksperymentu, planowanie, realizacja i statystyczne opracowanie wyników eksperymentów technologicznych. WNT Warszawa, 2006. 